\title{
Effect of age and season on sperm morphology of Friesland bulls at an artificial insemination centre in South Africa
}

\author{
D.M. Vilakazi and E.C. Webb \\ Department of Animal and Wildlife Sciences, University of Pretoria, Pretoria 0002, South Africa
}

\begin{abstract}
The primary objective of this study was to investigate the effect of age, season and the interaction between age and season on the sperm morphological characteristics of a selected population of Friesland bulls kept at an artificial insemination (AI) centre. The study was done at the Taurus AI station, South Africa with 271 Friesland AI bulls aged 12, 24, 36, 48, 60, 72, 84 and 96 months and older over a period of five years. Semen was collected by means of an artificial vagina in all four seasons of the year. Semen samples were screened for the percentage of normal sperm, percentage and total major defects (e.g. knobbed acrosomes, pyriforms, abnormal lose heads, dag defects, nuclear vacuoles, degenerative heads, mid-piece reflexes), the percentage and total minor defects (e.g. normal lose heads, distal droplets, curled end-piece and lose acrosomes). The results indicated that the percentage of normal sperm and major sperm defects were affected significantly by age of the bulls. Bulls at 36 to 48 months of age exhibited a better sperm morphology than bulls older than 72 months and bulls younger than 36 months of age. Major sperm defects that were affected by age included pyriform, knobbed acrosomes, mid-piece reflexes and dag defects. Season of the year also affected the percentage of normal sperm significantly. Percentage of normal sperm and major sperm defects were recorded as $72.8 \pm 1.6 \%, 79.4 \pm 2.2 \%, 82.5 \pm 2.4 \%$ and $84.4 \pm 2.4 \%$ and $20.3 \pm 1.3 \%$, $15.3 \pm 1.9 \%, 12.5 \pm 2.0 \%$ and $11.5 \pm 2.0 \%$ for summer, autumn, winter and spring, respectively. Major sperm defects such as proximal droplets and pyriform differed significantly with season. By contrast, knobbed acrosomes and mid-piece reflexes did not differ between seasons. Even though there was a wide variation in sperm morphology, better morphology was observed in spring and winter than in summer and autumn. Major sperm defects, particularly the prevalence of knobbed acrosomes and dag defects, were affected significantly by the interaction between age and season. Young bulls recorded a higher prevalence of major sperm defects during winter and old bulls a higher prevalence during the summer. It is concluded that age and season contribute significantly to the proportion of variation in the sperm morphological characteristics of Friesland AI bulls in South Africa. For successful AI programmes, semen collection in Friesland bulls should be done at 36 to 48 months of age and preferably during spring or winter.
\end{abstract}

Keywords: Age, season, sperm morphology, Friesland bulls

\#Corresponding author. E-mail: edward.webb@up.ac.za

\section{Introduction}

Artificial insemination (AI) is the most valuable breeding management tool available to dairy cattle breeders to improve the genetic potential of their herds. The collection of relatively large numbers of ejaculates containing the highest number of morphologically normal sperm is among the important factors determining the success of AI. Sperm morphology is used as one of the most important criteria in the evaluation of semen quality (Howard et al., 1983; Den Daas, 1992; Colenbrander et al., 1993; Bearden \& Fuquay 1997). Morrow (1980) defined the relationship between sperm morphology and the reproduction potential, and indicated that when more than $30 \%$ of the ejaculated spermatozoa have structural defects, reduced fertility may occur in domesticated animals. Considerable attention has been paid to the effect of age (Almquist \& Amann, 1976; Almquist, 1982; Everett \& Bean, 1982) and the season of collection (Mathevon et al., 1998) on sperm morphology of bulls. Fuente et al. (1984), Shannon \& Vishwanath (1995), Garner et al. (1996) and Mathevon et al. (1998) reported that the morphology of spermatozoa, sperm concentration, semen motility and the volume of the ejaculate improve with an increase in the age of bulls. Differences in factors such as feed quantity and quality (Siratskii, 1990; Castillo et al., 1987), environmental temperature and seasonal variations (McDowell, 1972) may also play a role in semen output. In areas where a seasonal variation in temperature occurs, sperm morphological characteristics have been found to be inferior during summer months (Curtis, 1983; Mathevon et al., 1998). Mathevon et al. (1998) reported that the interaction between age and season could have a significant effect on the semen characteristics of Friesland bulls. 
Furthermore, it was indicated that for young bulls, superior morphological characteristics were observed during the winter and spring compared to summer and autumn. Dombo (2002) reported that the semen quality does not remain the same throughout the year, especially as the animal advances in age. Therefore, the aim of this research was to study the effect of age, season and their interactions on the sperm morphological characteristics of Friesland AI bulls kept at an artificial insemination centre in South Africa.

\section{Materials and Methods}

The study was conducted at the Taurus Cooperative, Irene, (255' South, 28 $12^{\prime}$ East), South Africa. The Taurus AI station is situated in the Gauteng Province at an altitude of $1525 \mathrm{~m}$ above sea level. The long-term average rainfall of the area is $640 \mathrm{~mm}$ per annum, predominantly in summer (October to January). The dry season lasts from March to August, with a dry winter and spring from June to August.

The research was undertaken on 271 Friesland AI bulls over a period of five years. Each bull was used for more than one observation for the relevant variable regarding the effect of age, season and their interactions on sperm morphology. One observation was selected randomly from each bull. The age of the bulls ranged between 12 to 156 months. All bulls younger than 12 months and older than 150 months were discarded from the study. Eight classes were identified in this age range, as indicated in Table 1. Bulls were kept intensively and were fed $16 \mathrm{~kg}$ Eragrostis curvula hay and $4 \mathrm{~kg}$ of a $17 \%$ protein concentrate diet per $700 \mathrm{~kg}$ bull per day. Water was available ad libitum.

Table 1 Classification according to age group of Friesland bulls used at an artificial insemination centre for the analysis of sperm morphological characteristics

\begin{tabular}{ccc}
\hline Class & $\mathrm{n}$ & Months \\
\hline 1 & 02 & 12 to 23 months \\
2 & 66 & 24 to 35 months \\
3 & 40 & 36 to 47 months \\
4 & 48 & 48 to 59 months \\
5 & 51 & 60 to 73 months \\
6 & 44 & 74 to 83 months \\
7 & 8 & 83 to 95 months \\
8 & 12 & $\geq 96$ months \\
& Total 271 & \\
\hline
\end{tabular}

A standard bovine artificial vagina at a temperature of $42{ }^{\circ} \mathrm{C}$ was used to collect the semen from all bulls. During the semen collection process, a semen extender (Triladyl) was used as lubricant. The bulls were paraded around a teaser bull to increase the libido prior to semen collection. At least three false mounts were allowed prior to ejaculation to enhance the degree of sexual excitement. The collection of semen was performed twice weekly (Monday and Thursday or Tuesday and Friday). One ejaculate was collected from each bull during each collection. The collection of semen was scheduled through all seasons of the year. The number of observations obtained in each season varied according to the number of bulls utilised per season, as indicated in Table 2.

Table 2 Distribution of the number of bulls per season

\begin{tabular}{cccccc}
\hline Season & Autumn & Summer & Spring & Winter & Total \\
\hline No. of bulls & 44 & 109 & 58 & 60 & 271 \\
\hline
\end{tabular}

After the samples were collected, eosin-nigrosin smears were prepared to evaluate sperm morphology. A droplet of semen similar in size to the droplet of eosin-nigrosin was placed on a clean slide. The mixture was incubated at $37^{\circ} \mathrm{C}$ to allow the eosin stain to penetrate the defective sperm membranes. The smear was then dried at $37^{\circ} \mathrm{C}$. Immediately after drying, the smear was placed under the microscope to inspect the technical quality and freedom of artefacts. The evaluation of sperm morphology was performed 
using 1000x magnification. Sperm cell abnormalities were grouped into major and minor defects (Society for Theoriogenology, 1976) and expressed as a percentage of the total number of cells counted. The incidence of major defects such as terratoid, knobbed acrosomes, pyriform, nuclear vacuoles, nuclear ridges, macrocephallic, microcephallic, abnormal lose heads, double forms, degenerated heads, cork screw, midpiece reflexes, dag defects, broken flagellum, proximal droplets and minor sperm defects such as normal lose heads, loose acrosome, curled end-piece and distal droplets were recorded.

Statistical analyses of the data were done using the general linear model (GLM) procedure of the Statistical Analysis System (SAS, 1999). Analysis of variance on the effect of season was done by means of the GLM procedure and least square means (LSM) option, while age was used as a continuous variable. The effect of age in different age groups was analysed using the "at that" (AT) value option of the general linear model (GLM) procedure, which made it possible to select realistic and logical co-variates. A similar procedure was used for the analysis of variance for the interactions between age and season.

\section{Results and Discussions}

The results recorded indicated that age had an influence on the percentage of normal sperm $(\mathrm{P}=$ 0.05). Figure 1 illustrates that the percentage of normal sperm was higher for bulls aged 36 to 48 months than for bulls younger than 36 months and older than 72 months of age. The percentages of normal sperm were above $70 \%$ in all age groups, which is acceptable for semen morphology, according to Coe (1999).

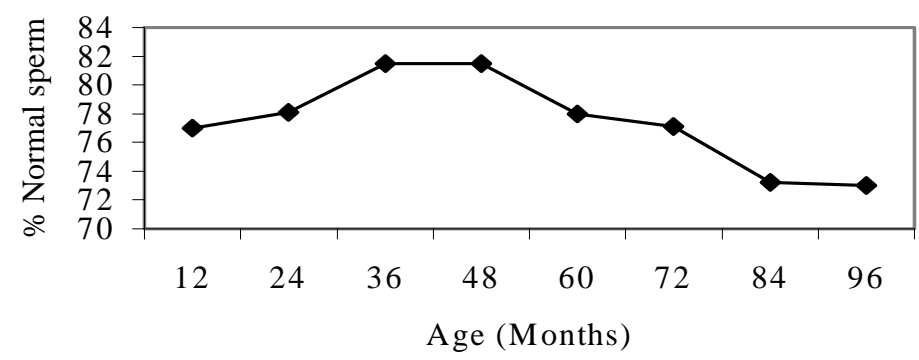

Figure 1 The effect of age on the percentage of normal sperm in semen collected from Friesland bulls at an artificial insemination centre

Age also influenced the percentage of major sperm defects $(\mathrm{P}=0.01)$ which was lower in bulls of 36 to 48 months of age, than bulls younger than 36 months of age and older than 72 months of age (Figure 2). Major sperm defects that were affected by age included pyriform $(P=0.03)$, dag defects $(P=0.02)$, knobbed acrosomes $(\mathrm{P}=0.02)$ and mid-piece reflexes $(\mathrm{P}=0.01)$. The results of this study are in agreement with that of Kumi-Diaka et al. (1981), Dowsett \& Knott (1996) and Soderquist et al. (1996) in that the variation in the percentage of normal sperm and the frequency of abnormal sperm increased with ageing. On the other hand, the study indicated that age did not affect the percentage of minor sperm defects. This is contrary to the results obtained by Brito et al. (2002) who observed a significant increase in the percentage of minor sperm defects with ageing in bulls.

Overall, the results indicate that the best sperm morphology was obtained in mature bulls between 36 and 48 months of age rather than in bulls younger than 36 or older than 72 months of age. Better semen morphology in mature bulls compared to younger and older bulls may probably be due to scrotal circumference (Brito et al., 2002) and the heat regulation mechanisms (McDowell, 1972), which increase with age. Scrotal circumference, which is positively correlated with sperm morphology (Barth \& Oko, 1989; Vale Filho et al., 1997) increased rapidly in younger bulls, gradually in mature bulls and tended to decrease in older bulls (Coulter \& Foote, 1977). Dairy bulls often reach puberty at the age of 10 to12 months (Bearden \& Fuquay, 1997) and maturity at the age of 3 to 4 years (Almquist, 1982). Prior to maturity, the reproductive system in bulls, particularly testicle size (Coulter \& Foote, 1977) and thermo-regulatory mechanisms (McDowell, 1972) are still developing. As a consequence, a higher proportion of sperm defects may appear in the ejaculate of bulls prior to maturity (Bearden \& Fuquay, 1997) than in older bulls. As bulls advance in 
age testicular tissues may be broken down faster than being replaced (King, 1993). This may result in testicular degeneration and abnormal scrotal thermograms, and hence poor sperm morphology in older bulls.

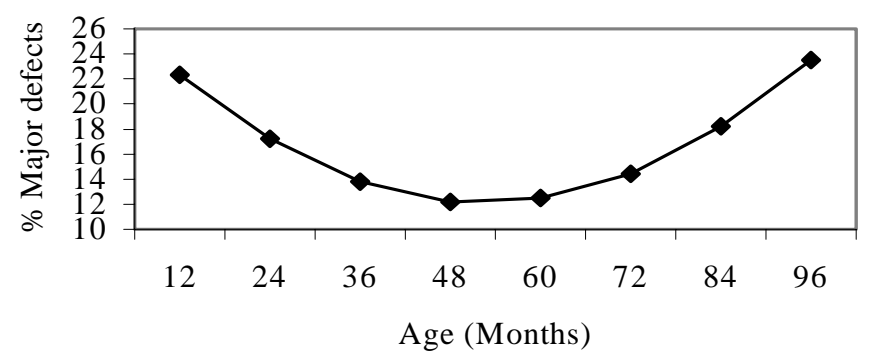

Figure 2 Effect of age on the percentage major sperm defects in semen collected from Friesland bulls at an artificial insemination centre

The results of the present study indicated that season affected $(\mathrm{P}=0.01)$ the percentage of normal sperm, and major and minor sperm defects. Table 3 illustrates that during the summer, autumn, winter and spring seasons, the percentages of normal sperm were $72.8 \pm 1.6 \%, 79.4 \pm 2.2 \%, 82.4 \pm 2.4 \%$ and $84.4 \pm 2.4 \%$, respectively.

Table 3 Effect (least square means \pm s.e.) of season on sperm morphological characteristic of Friesland bulls at an artificial insemination centre

\begin{tabular}{lccccc}
\hline $\begin{array}{c}\text { Semen defects } \\
\%\end{array}$ & Summer & Autumn & Winter & Spring & P value \\
\hline & & & & & \\
Normal sperm & $72.8 \pm 1.6^{\mathrm{A}}$ & $79.4 \pm 2.2^{\mathrm{B}}$ & $82.5 \pm 2.4^{\mathrm{B}}$ & $84.4 \pm 2.4^{\mathrm{B}}$ & 0.01 \\
Major defects & $20.3 \pm 1.3^{\mathrm{B}}$ & $15.3 \pm 1.9^{\mathrm{A}}$ & $12.5 \pm 2.0^{\mathrm{A}}$ & $11.5 \pm 2.0^{\mathrm{A}}$ & 0.01 \\
Knobbed acrosome & $1.2 \pm 0.2$ & $1.0 \pm 0.3$ & $1.4 \pm 0.3$ & $0.8 \pm 0.3$ & 0.37 \\
Pyriform & $8.2 \pm 0.7^{\mathrm{B}}$ & $6.6 \pm 0.1^{\mathrm{AB}}$ & $3.7 \pm 1.1^{\mathrm{AC}}$ & $5.0 \pm 1.07^{\mathrm{A}}$ & 0.01 \\
Mid-piece reflex & $3.1 \pm 0.4$ & $2.6 \pm 0.6$ & $4.1 \pm 0.7$ & $3.4 \pm 0.6$ & 0.36 \\
Proximal droplets & $4.4 \pm 0.5^{\mathrm{C}}$ & $2.3 \pm 0.7^{\mathrm{BC}}$ & $1.7 \pm 0.8^{\mathrm{B}}$ & $1.1 \pm 0.8^{\mathrm{A}}$ & 0.03 \\
\hline
\end{tabular}

\footnotetext{
${ }^{\mathrm{A}-\mathrm{C}}$ Means in the same row with different superscripts differ significantly $(\mathrm{P}<0.05)$
}

Although the percentage of normal sperm ranged between 70 to $90 \%$ in different seasons, which is acceptable (Coe, 1999), the effect of season on the percentage of normal sperm was significant. Figure 3 demonstrates a higher percentage of normal sperm in spring and winter than in summer and autumn. There was an increase $(\mathrm{P}=0.01)$ of $10.2 \%$ in the percentage of normal sperm from summer to winter and a decrease $(\mathrm{P}=0.01)$ of $11.6 \%$ from spring to summer.

The percentages of major sperm defects during summer, autumn, winter and spring were $20.3 \pm 1.3 \%$, $15.3 \pm 1.9 \%, 12.5 \pm 2.0 \%$ and $11.5 \pm 2.0 \%$, respectively (Table 3 and Figure 4). Although the percentage of major sperm defects was below $20 \%$ during all seasons, which is considered acceptable (Bearden \& Fuquay 1997; Coe 1999), significant $(\mathrm{P}=0.01)$ differences were observed between all the seasons (Table 3).

Figure 4 indicates that a higher percentage of major sperm defects was recorded during summer, than in winter and spring $(\mathrm{P}=0.01)$, and shows an increase $(\mathrm{P}=0.01)$ of $8.8 \%$ from spring to summer and a decrease $(\mathrm{P}=0.02)$ of $5.0 \%$ from summer to autumn. The major sperm defects affected by season were proximal droplets $(\mathrm{P}=0.03)$ and pyriform $(\mathrm{P}=0.01)$. Other defects such as knobbed acrosomes and midpiece reflexes did not differ significantly between season (Table 3). Based on the report by Salisbury et al. (1978), minor sperm defects have a significant effect on semen quality only when exceeding $10 \%$. This trail showed minor sperm defects in the summer, autumn, winter and spring seasons, viz. $7.9 \pm 0.6 \%, 6.2 \pm 0.9 \%$, $6.3 \pm 0.2 \%$ and $5 \pm 0.2 \%$, respectively. Even though the results indicated that minor defects varied $(\mathrm{P}=0.03)$,

The South African Journal of Animal Science is available online at http://www.sasas.co.za/Sajas.html 
the incidence was below the critical level of $10 \%$. Despite this, the incidence of minor defects tended to increase towards the critical level in summer. The overall results of the present study suggest that summer is a critical season for semen collection in Friesland bulls at this AI centre in South Africa due to the lower percentage of normal sperm and higher incidence of sperm defects. These findings agree with those of Curtis (1981), Mathevon et al. (1998) and Corcuera et al. (2002) who reported higher variation and lower semen quality in summer than in the other seasons. The results obtained in the present study may be due to a higher ambient temperatures during summer, which may result in a reduction in scrotal circumference (Downey et al., 1984) and feed intake (McDowell, 1972), degenerative changes in the semniferous tubules (Kumi-Diaka et al., 1981) and hence inferior semen quality (Lunstra \& Coulter, 1997). In agreement with the results of this study, Barth \& Oko (1989) concluded that the incidence of defects such as pyriform and midpiece reflex was more prevalent during abnormal conditions which modify testicular function by either a disturbance of heat regulation or of the endocrine function of the testis, which both occur during exposure to extreme temperatures than under normal conditions.

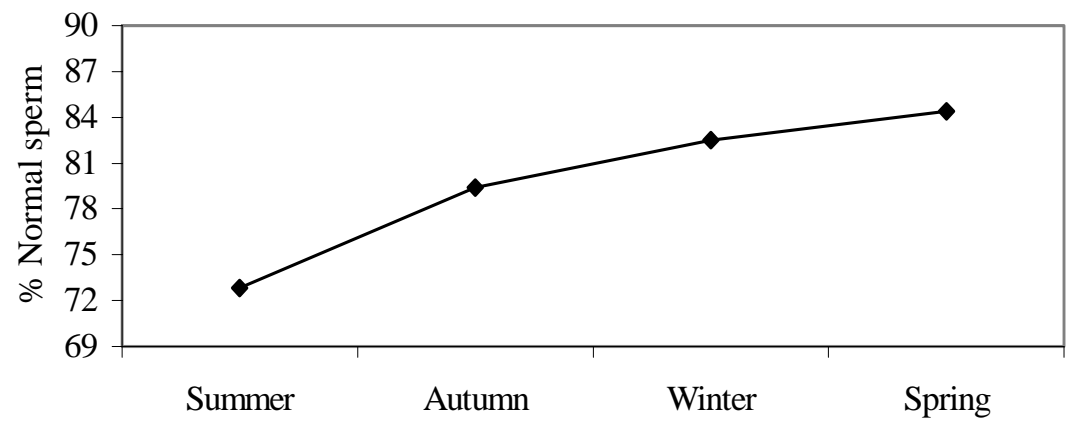

Figure 3 The effect of season on the percentage of normal sperm in semen collected from Friesland bulls at an artificial insemination centre

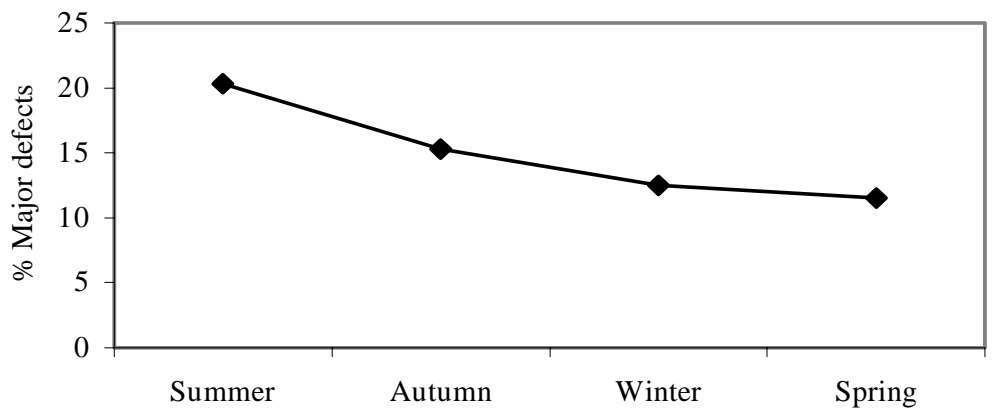

Figure 4 The effect of season on the percentage of major sperm defects in semen collected from Friesland bulls at an artificial insemination centre

No significant interactions were recorded for age and season on percentage of normal sperm or minor defects. However, an interaction between age and season on the percentage major sperm defects $(\mathrm{P}=$ 0.05) was recorded (Figure 5). 


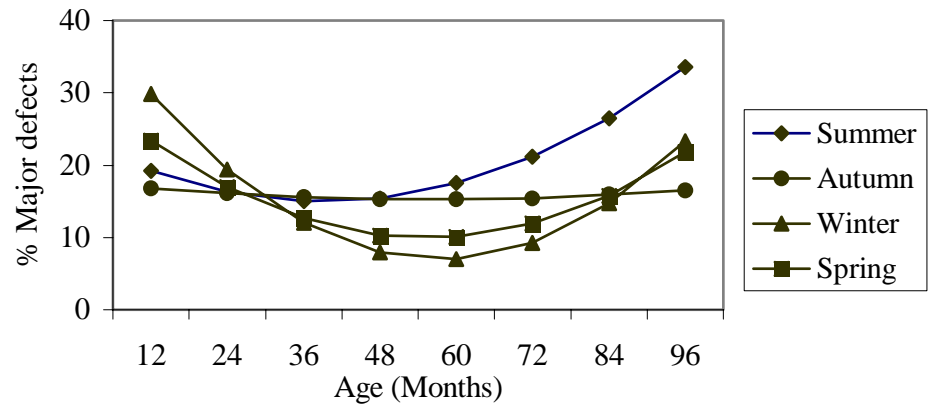

Figure 5 The interaction between age and season on the percentage of major sperm defects in semen collected from Friesland bulls at an artificial insemination centre

Major sperm defects that were affected by the interaction between age and season in Friesland AI bulls were knobbed acrosomes $(\mathrm{P}=0.05)$ and dag defects $(\mathrm{P}=0.05)$. Figure 5 suggests that winter was critical for bulls younger than 36 months as the incidence of major defects during this season exceeded 20\%, which is critical, according to Salisbury et al. (1978), Bearden \& Fuquay (1997) and Coe (1999). The effect of winter on sperm morphology declined drastically up to 60 months of age and then increased but to a lesser degree between 60 and 96 months of age. Summer was less of a concern in bulls younger than 36 months of age, but had a greater and increasing influence than all the other seasons. These results are contrary to those of Salisbury et al. (1978) who observed a higher performance in bulls younger than 36 months during winter and a decline in the subsequent warmer seasons. Figure 5 also shows no significant variation in sperm morphology of bulls between 36 and 48 months of age, with season. As bulls advanced in age, however, they became more susceptible to major sperm defects during summer compared to the other seasons. The effect of the interaction between age and season may probably be attributed to factors such as heat regulating mechanisms and fat deposition and the fate of body tissues between bulls of different ages in different seasons. Fat deposition, which increases with age (King, 1993) may also take place in the scrotum (Barth \& Oko, 1989; Coulter et al., 1997) and lower the efficiency of scrotal thermo-regulation during summer in old bulls by reducing the amount of heat that can be radiated from the scrotal neck. Thus, an abnormal scrotal thermogram may occur and hence inferior semen quality will be produced.

\section{Conclusions}

It can be concluded that the age and season when semen is collected influence the morphological characteristics of sperm of Friesland AI bulls. The practical implications are that the collection of semen of Friesland AI bulls should be performed between the ages of 36 and 48 months and preferably in spring or winter. Summer is not the ideal season for the collection of semen in old bulls, and winter is also critical for young bulls.

\section{Acknowledgements}

The authors would like to thank W. de Boer (Taurus Electron) and the University of Pretoria for financial support. The assistance of E.P. Arndt (Taurus Coop) and W. Anderson for the collection and analyses of semen samples, H.T. Groeneveld and R. Owen (Department of Statistics, University of Pretoria) for the statistical analyses of the data and D.E. Louw (Department of Animal and Wildlife Sciences, University of Pretoria) for administrative support is gratefully acknowledged.

\section{References}

Almquist, J.O., 1982. Effect of long term ejaculation at higher frequency on out put of sperm, sexual behaviour and fertility of Holstein bulls relation of reproduction capacity to higher nutrient allowance. J. Dairy Sci. 65, 815-882.

Almquist, J.O. \& Amann, R.P., 1976. Reproductive capacity of dairy bulls. XI. Puberal characteristic and post puberal changes in production of semen and sexual activity of Holstein bull ejaculated frequently. J. Dairy Sci. 59, 986-991. 
Barth, A.D. \& Oko, R.J., 1989. Abnormal morphology of bovine spermatozoa. Iowa State University Press, Ames.

Bearden, H. \& Fuquay, J.W., 1997. Applied animal reproduction. (3th ed.). Prentic-Hall, Englewood Cliff.

Brito, L.F.C., Silva, A.D.E.F., Rodrigues, L.H., Vieira, F.V., Deragon, A.G. \& Kastelic, J.P., 2002. The effect of environmental factors, age, and genotype on sperm production and semen quality of B. indicus and B. taurus AI bulls in Brazil. Theriogenology 70, 181-190.

Castillo, E., Tizol, G., Alverez, J.L., Perez, M. \& Baez, R., 1987. Reduction of protein concentrates level in ratio for Holstein sires. 1. Effect on semen quality. Cuban J. Agric. Sci. 21, 247-251.

Coe, P.H., 1999. Association among age, scrotal circumference and proportion of morphological normal spermatozoa in young beef bulls during an initial breeding soundness examination. J. Am. Vet. Med. Assoc. 214, 1664-1667.

Colenbrander, B., Fustma, H. \& Gooten, H.J., 1993. Optimising semen production for AI in swine. J. Reprod. Fertil. Suppl. 48, 207-215.

Corcuera, B.D., Hernandez-Gil, R., De Alba Romeo, C. \& Martin-Rillo, S., 2002. Relationship of the environmental temperature and in boar facilities with seminal quality. Livest.. Prod. Sci. 71, 55-62.

Coulter, G.H. \& Foote, R.H., 1977. Relationship of body weight to testicular size and consistency in growing Holstein bull. J. Anim. Sci. 44, 1076-107.

Coulter, G.H., Cook, R.B. \& Kastelic, J.P., 1997. Effects of dietary energy on scrotal surface temperature, seminal quality and sperm production in young bulls. J. Anim. Sci. 75, 1048-1052.

Curtis, S.E., 1983. Environmental management in animal agriculture. Iowa State University Press.

Den Daas, N., 1992. Laboratory measurement of semen characteristics. Anim. Reprod. Sci. 28, 87-94.

Dombo, H.M., 2002. Seasonal effect on semen quality of Gorno Altai and South African indigenous goats. M. Inst. Agrar. thesis, University of Pretoria, South Africa.

Downey, R.B., Pierce, A.R \& Sanford, L.M., 1984. Seasonal variation in pituitary and testicular function in bulls. $10^{\text {th }}$ Int. Cong., Anim. Reprod. AI. 142 pp.

Dowsett, K.F \& Knott, L.M., 1996. Influence of age and breed on stallion semen. Theriogenology 46, 397412.

Everret, R.W. \& Bean, B., 1982. Environmental influences on semen output. J. Dairy Sc. 65, 1303-1310.

Fuente, L.F., Sanchez-Garcia, L. \& Vallejo, M., 1984. Reproductive characters in Galician Blonds. Characters of semen used in AI. Anal. Fac. Vet. Leon. 30, 119-125.

Garner, D.L., Johnson, L.A., Allen, C.H., Palencia, D.D. \& Chamber, C.H., 1996. Comparison in semen quality in Holstein bulls as yearling and as mature sires. Theriogenology 45, 923-934.

Howard, J.G., Wildt, D.E., Chakraborty, P.K. \& Bush, M., 1983. Reproductive traits including seasonal observation on sperm quality and serum hormone concentration in Dorcas Gazelle. Theriogenology 20, 221-234.

King, G.J., 1993. Reproduction in domesticated animals. Elsevier Science Publisher B.V. London, New York.

Kumi-Diaka, J., Nagerathman, V. \& Rwuaan, J.S., 1981. Seasonal, age- related changes in semen quality and testicular morphology of bulls in tropics. Vet. Rec. 108, 13-15.

Lunstra, R.P. \& Coulter, G.H., 1997. Relationship between scrotal infrared temperature pattern and natural mating fertility in beef cattle. J. Anim. Sci. 75, 767-774.

Mathevon, M., Bhyr, R.M. \& Dekkers, J.C., 1998. Environmental, management, and genetic factors affecting semen production in Holstein bulls. J. Dairy Sci. 81, 3321-3330.

McDowell, R.E., 1972. Improvements of livestock production in warm climates. Cornell University. Wlt, Freeman and Company, NY.

Morrow, D., 1980. Current theraphy in theriogenology. W.B Saunders Co. Philadelphia.

Salisbury, G.W., Van Denmark, M.L. \& Lodge, J.R., 1978. Physiology of reproduction and AI of cattle. W.N. Freeman and Co. San Fransisco.

SAS, 1999. Statistical Analyses System user's guide (8th ed., Vol. 2). SAS Institute Inc., Cary NC, USA.

Shannon, P. \& Vishwanath, R., 1995. The effect of optimal and sub-optimal concentration of sperm on the quality of fresh and frozen bovine semen. Anim. Reprod. Sci. 39, 1-10.

Siratskii, Z.I., 1990. Inheritance of reproductive ability of bulls. Tsitol. Genetics 24, 28-34.

Society for Theriogenology., 1976. A compilation of current information on breeding soundness evaluation and related subjects. Journal Volume 7. 
Soderquist, L., Janson, L., Haard, M. \& Einarsson, S., 1996. Influences of season, age and breed and some other factors on the variation in sperm morphological abnormalities in Swedish dairy AI Bulls. Anim. Reprod. Sci. 44, 91-98.

Vale Filho, V., Bergman, A.J., Andrade, V.J., Quirino, C.R., Reis, R.S. \& Mendoca, R.M, 1997. Andrological characteristics of Nelore bulls for the first breeding season. Rev. Bras. Reprod. Anim. 21, 42-45. 